\title{
Schools as Equitable Communities of Inquiry
}

\author{
Robert Riordan and Stacey Caillier
}

\section{INTRODUCTION}

In a working paper on sustainable well-being, the Sitra Foundation (2015) emphasizes schools as centers of transformative action to address the twin challenges of diversity and complexity in the emerging world:

The future school has to answer the needs of an increasingly complex and global world and raise youth to collaborate and work in networks with people from different backgrounds. Instead of studying theory alone, learning happens by experiencing together. The problem to be solved is outlined together and knowledge is gathered and assumptions tested in concrete experiments outside the school building. (p. 17)

R. Riordan $(\bowtie)$

High Tech High Graduate School of Education, San Diego, CA, USA e-mail: rriordan@hightechhigh.org

S. Caillier

Center for Research on Equity and Innovation, High Tech High Graduate School of Education, San Diego, CA, USA

e-mail: scaillier@hightechhigh.org

(C) The Author(s) 2019

J. W. Cook (ed.), Sustainability, Human Well-Being, and the Future of Education, https://doi.org/10.1007/978-3-319-78580-6_4 
What would such a school look like, in the face of an uncertain future? In its attention to diversity and action, it would ignore the basic axioms of twentieth-century schooling, i.e., separate students into "tracks," divide knowledge into "subjects," and hold school separate from the world. Instead, the school would integrate students, engage in transdisciplinary study, and connect with the community. It would foster self-directed learning, individual and collective agency, and the passionate pursuit of important questions.

If this is the project, what issues of purpose and practice arise? How can schools achieve the agility, not only to adapt to a changing environment, but also to engage in transformative action? What roles must the teacher assume in such a setting, and what kinds of training and development will be necessary?

In this chapter, we argue that life in schools, like life in a well-being society, should be coherent-that is, comprehensible, manageable, and purposeful (Hämäläinen 2014). The diversity of our students, the complexity of the world, and the urgency of our current condition demand a paradigm shift where schools, rather than purveyors of inert knowledge, serve as centers of community inquiry and action. We take inspiration from the philosophy and methodology of John Dewey (1938), in his emphasis on the connection between experience and education, and Paulo Freire (1998), in his insistence on the educator's responsibility to help students understand their own reality and take transformative action in the world, as well as the work of Timo Hämäläinen (2014) and colleagues on sustainable well-being. The sense of urgency comes, as well, from our growing awareness of the mental and physical toll of a stressful school environment, which has reached the level of a child/adolescent mental health crisis in the USA (Abeles 2015).

We define equity in schools as a condition where everyone exercises voice and choice, engages in work that is accessible and challenging, and connects with the world beyond school-in short, where all have access to deeper learning experiences that prepare them to lead a purposeful life once they graduate. We link equity to sustainability because the world in every corner is becoming more diverse, a phenomenon that problematizes the issue of equity as a subject for inquiry, action and reflection. In a world where schools lack a common narrative to inspire and engage (Postman 1995), we see equity and sustainability as viable purposes of schooling, not simply subjects for study. We espouse a general principle of integration, and we imagine schools as reflective communities of 
inquiry that grapple with questions of equitable teaching and learning in a diverse setting.

Drawing on our work at High Tech High in San Diego, we propose principles and processes for schools as equitable communities of inquiry. Indeed, the future school we envision is not an achieved state, nor will it ever be, in a rapidly changing world. Rather, it is a reflective, selfrenewing, cross-generational community, well situated to conduct inquiry and take action on questions of purpose and practice: who are we, what kind of community do we envision, and how do we move forward together?

\section{The Pursuit of Questions}

What questions, concerns or wonders do you have about the world? About your life?

These questions await the 54 students in Bobby Shaddox and Allie Wong's combined 6th grade class as they rush in from break. The students, broadly diverse by race, ethnicity, socio-economic circumstances, and prior academic achievement, look at the whiteboard and then at each other with excitement and a little puzzlement. Bobby and Allie quickly get them oriented to the task at hand, and they begin filling up post-it notes with their questions. For 25 minutes students dream, ponder, and wonder. Then they begin sharing their questions.

How can we turn salt water into drinkable water?

How could we make a car that would run on trash?

How can we stop global warming?

Why am I angry?

Why do people hurt each other?

As they share in small groups and post their questions on the walls, the students begin to identify themes. Many of these have to do with the beginning of life, the end of the world, and the role that humans play in both. As a class, after days of discussion, they craft an essential question for their collective project: What are the ways in which the world might end, and what can humans do to prevent it?

Over the next three months, students work in partnerships to explore questions within this broader theme. The questions connect, in one way 
or another, to science, math, and humanities, the cluster of subjects for which Bobby and Allie are responsible. However, they are not simply entry points for subjects - they are life questions. Some students study black holes; others investigate the Mayan calendar, tsunamis, hurricanes, epidemics, volcanos, war, deforestation, climate change, tectonic plates, or meteor impacts. Students reach out to living resources, visiting online or in person with experts in India, in Hawaii, at local universities and museums, and elsewhere in the community. Throughout the project, the students employ consensus processes and committees to make decisions about everything from the final product to the audience to the timeline. In the end, they organize a public exhibition to introduce their book, The End of the World Uncovered (2012), filled with original art and writing, the product of many rounds of peer critique and revision (see Fig. 4.1).

Exhibition plays a special role at Bobby and Allie's school, High Tech Middle, as the prospect of an authentic audience has an enormous impact on the quality of student work. Moreover, exhibitions serve as a powerful community organizing tool, as students insist that their families and friends turn out to see what they've done. On the night of the annual all-school exhibition, when each student presents work, it is nearly impossible to find a parking place for blocks around, and hard to move inside the building, it is so crowded. ${ }^{1}$

Bobby and Allie are not alone in this work. In a kindergarten class at High Tech Elementary in Chula Vista, teachers pose a similar question to students: What are your questions about yourself and the world? Many of them are wondering about caterpillars, since there is an infestation of caterpillars in the trees and shrubs around the school. They develop an exhibition called "Caterpillar Café - Everything You Ever Wanted to Know about Caterpillars." Seniors at HTH International, in response to the same question, mount a research project and compose a volume of articles on how adults view-and often misperceive-adolescents. At High Tech High, 11th grade students have engaged in an ongoing study of San Diego Bay under the direction of biology teacher Jay Vavra and humanities teacher Tom Fehrenbacher. Each successive year, juniors publish a book on some aspect of the Bay-the fauna, history of the Bay, the impact of human activity, the potential of biomimicry for remediation (Fehrenbacher 2015). Other classes may interview military veterans, write a book on economics, produce a documentary on gun violence, design assistive devices for clients of a local health agency, or develop a DNA 


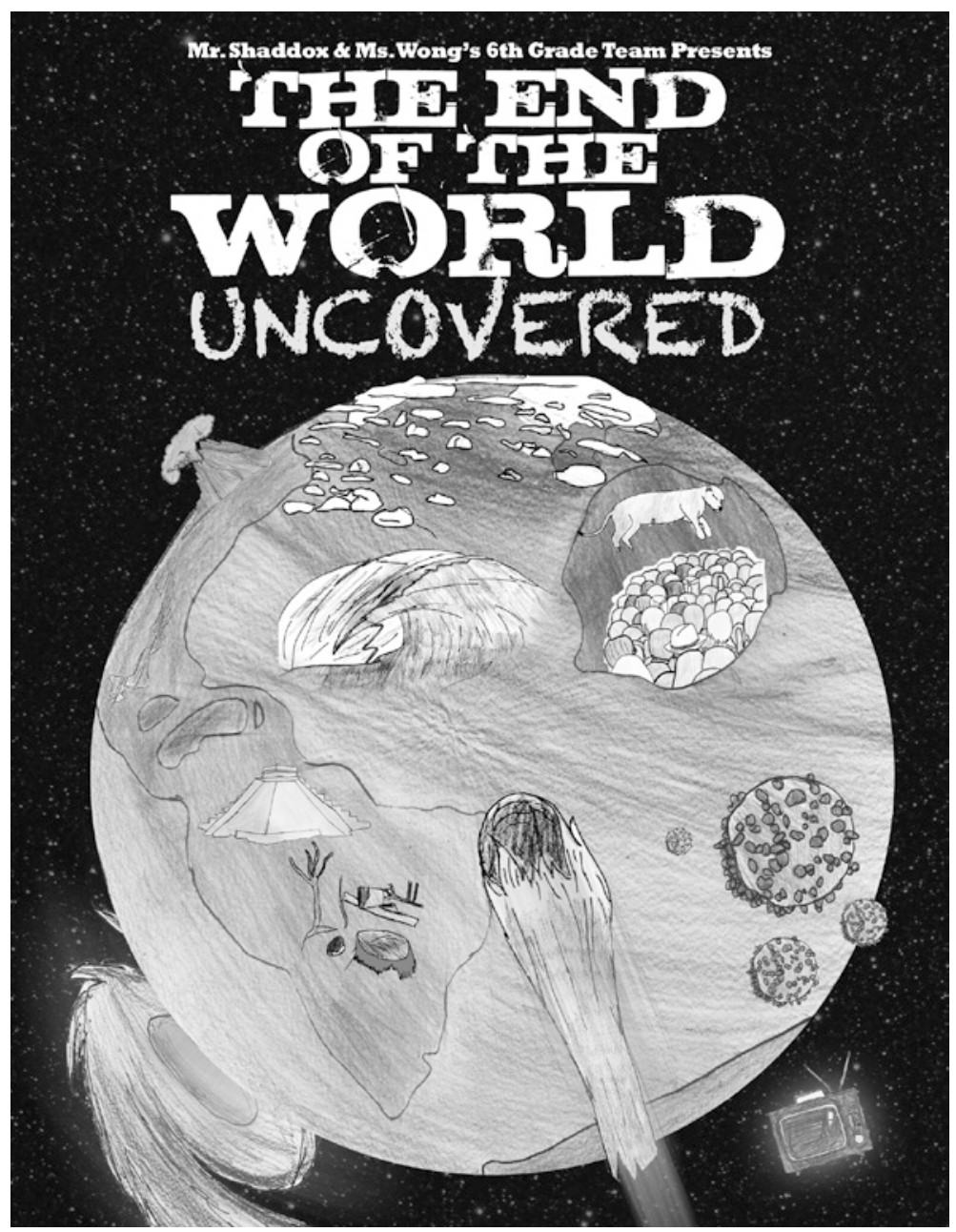

Fig. 4.1 Cover, The End of the World Uncovered

barcoding device for species identification from meat samples. Across the 13 High Tech High schools- 4 elementary, 4 middle, and 5 high-this is the aspiration: to pursue important questions and share findings, with the goal of fostering individual agency in a community of learners. 
As their students uncover the end of the world, Bobby and Allie are pursuing a question of their own: What happens when we co-design projects with students? (Shaddox 2013). Indeed, they work in an organization where the pursuit of such questions is taken seriously and supported as part of teachers' work, both at their school and in an embedded High Tech High Graduate School of Education (GSE), devoted to building leadership capacity within the organization and beyond. Through the graduate school, and through GSE-supported "improvement groups" in the K-12 schools, teachers have studied a wide range of questions regarding purpose and practice, ${ }^{2}$ e.g.:

How can we make group work more equitable?

How can we ensure that all students have a meaningful internship experience?

How can we use peer critique to improve the quality of student writing and develop a culture of collaboration in our classrooms?

What prevents "chronically absent" students from coming to school, and what can be done?

How can we increase students' sense of agency and authority in math, so they learn to trust their own thinking and value the thinking of their peers?

How can we cultivate a sense of belonging and strengthen peer networks among boys of color so they experience academic success in our schools and beyond?

What does it mean for schools to serve as equitable communities of inquiry? To begin with, it means that we honor questions more than answers. And if, as in Bobby and Allie's classroom, we start with diverse students posing questions about themselves and the world, we bump smack up against the culture of conventional schooling: management structures, grouping practices, curriculum, pedagogy, assessment, teacher development, and relationships with the larger community. Transforming schools into centers of equity and sustainability requires a paradigm shift, along with the commitment, dispositions, and processes to drive continual improvement as educators and students engage together in work that matters. 


\section{STRUCTURES THAT LibERATE}

You can tell everything you need to know about a school's priorities by the way it allocates adult and student time and resources.

- Theodore Sizer, American educator

Anybody can make the simple complicated. Creativity lies in making the complicated simple.

—Charles Mingus, American jazz bassist and composer

Current structures (by which we mean the way schools allocate adult and student time and resources) complicate life in schools, especially in middle and high schools. The great irony is that conventional school management structures, put into place a century ago with the aim of industrial-style efficiency, end up being horribly inefficient for effective teaching and learning. A typical middle- or high-school student goes to six or seven different "stations" per day and receives several different "homework" assignments, for which she is accountable to several different teachers. And the teachers? A typical high school teacher sees as many as 180 students per day, teaches in isolation, and rarely engages in professional activity with colleagues except in perfunctory monthly department meetings or one-size-fits-all "professional development." There's nothing coherent or purposeful about these structures, for teachers or students. For the most part, despite the best efforts of educators, schools are control centers of inequity and alienation, except for certain extra-curricular activities, such as after-school athletics or school plays, where the aim is not "coverage," but, rather, public exhibition or performance.

The conventional structures are not only complicated, but also inequitable, by design. Donald Berwick, a founder of improvement research in health care, has noted that "every system is perfectly designed to achieve exactly the results it gets." 3 The starting point for education for equity is to understand that conventional schooling in the USA, as a system, is structured for inequitable access (Oakes 1985). The ubiquitous practice of separating students based on presumed ability, as reinforced by standardized tests that value a narrow band of intelligence, along with a curriculum based on narrowly construed and confining "subjects," not to mention the housing patterns and districting practices that yield school populations more segregated than before Brown v. Board of Education (Orfield 2009), guarantees inequitable outcomes. Moreover, 
these structures - the "existing regularities" of school culture (Sarason 1982) - are remarkably resilient and resistant to change.

In The End of Education (1995), Neil Postman observed that no "transcendent and honorable purpose" drives the activity in public schools and that, if schools do not find their end, as in purpose, they will meet their end as in demise $(\mathrm{x}-\mathrm{xi})$. In other words, education without purpose is unsustainable. Achieving high tests scores is not a compelling purpose, especially for students and schools that don't score well, year after year. Indeed, schools are stuck with the cross-purposes of sorting and equity, responsible both to sort students according to their "readiness" and to ensure equitable outcomes. This is a false dichotomy, based in a narrow conception of readiness and resolvable by adopting equity and agency as the essential purposes of schooling.

What are the structural features of a sustainable, equitable learning environment? How might the school experience be more coherent and less alienating, for both students and teachers? What are the structures that liberate- that promote engagement and unleash energy?

We see such structures in Bobby and Allie's classroom, and in the larger context in which they work. Students at their school, High Tech Middle, are selected by a blind, postal-code based lottery, so as to represent the demographics of the school-age population in the city. ${ }^{4}$ Once in the school, students are not tracked or streamed. Instead, they are assigned randomly to classes, with an eye toward assuring that each classroom mirrors the overall diversity of the school. They move through the day in stable cohorts, each served by a team of teachers who share the same students as they collaborate in transdisciplinary work. Teachers function as co-designers, responsible for the curriculum in their classroom. Teachers may say, "We teach what we want," and they do, but all teachers are accountable to a common set of design principles, and teacher autonomy is mediated through collaboration and dialogue, as teachers routinely share their designs and samples of student work with each other. The schedule supports this sharing and other forms of collaboration, as teachers arrive at school each day one hour before the students arrive. The physical structure also supports collaboration, as well as the organizational emphasis on transparency, with moveable dividers between classrooms, flexible open spaces, and lots of glass. Students participate in defining these spaces. For example, eighth graders redesigned and rebuilt their double classroom to include counter spaces along the walls, comfortable seating, and work tables. 
These are integrative structures. Bobby's school, like all HTH schools at all age levels, ignores the basic axioms, noted earlier, by which American schools separate students into "higher" and "lower" tracks, separate content into subjects (and in particular, separate "academic" and "technical" subjects), and separate school from the world at large. Instead, the school integrates students, subjects, and the arenas of school and world. Putting students from vastly different backgrounds in the same classroom poses a formidable challenge for teachers, but it is a challenge the organization embraces, rather than suffer the pernicious effects of separating children, per conventional practice, by presumed academic readiness, which in practice correlates strongly with race, ethnicity, and social class.

These structures for equity have the virtue of simplicity. Compared to the comprehensive high school, the program offers fewer choices of courses. Instead, choice has been relocated inside the classroom, as students pursue questions through projects. Teachers typically carry a student load of 60 students for core academic work. Students go to a maximum of three "stations" during the day, and often just one or two, in the case of integrated projects, making the daily and longer-term experience of schooling, not only equitable, but also comprehensible, manageable, and purposeful - the hallmarks of a well-being institution (Hämäläinen 2014). We want students, when asked what they're working on, to describe a project, rather than say that they go to math at 9:04, English at 9:52, and so on. Within such simplified, integrated structures, teachers get to know students well and build learning communities in their classrooms.

High Tech High is a principles-based initiative. Its design principles, shared across the 13 schools, offer a frame of reference for decision making across the organization. In particular, they offer a lens for examining teacher and student work, especially with regard to equity. The principle of personalization asks the question, with respect to teacher designs and student work, "Where in this work do we see evidence that all students are exercising voice and choice?" The overriding principle of equity, by which the organization commits to untracked classrooms, leads to the question, "Where in this work do we see evidence of access and challenge for all students?" The principle of authentic work triggers the question, "Where in this work do we see evidence that students are making authentic connections with the world beyond school?" A fourth 
principle, collaborative design, raises the question, "What structures are in place to support the design work of teachers and students?"

The point here is not that other educators need copy High Tech High, but rather that the equitable and sustainable school of the future, in its various iterations, attends closely and persistently to the alignment of purpose and structure. For example, if we value authentic work, we might make field work and internships central to the program and embed support for them within the structure of the school; if we value teachers as co-designers, we must build in time for them to collaborate; if we value personalization, ${ }^{5}$ we might introduce an advisory program where students can be known well, or reduce the student load per teacher. Overall, if we want to fully support effective and equitable teaching and learning, a comprehensive approach is required: reconfigure the day, group students and staff together in cohorts, eliminate tracking, and reorganize the curriculum toward coherence and connection. Design principles offer a frame of reference for discussions about planning, projects, and progress in this transformation.

\section{Rethinking THe CURRICUlum}

Early in the twentieth century, Alfred North Whitehead (1929) lamented that, while "in the schools of antiquity philosophers aspired to impart wisdom, in modern colleges our more modest aim is to teach subjects" (p. 29). Indeed, subjects are at the heart of our modern dilemmaour inability to achieve both excellence and equity-for two reasons. First, the artificiality and the arbitrary origins of subjects (Wagner and Dintersmith 2015) mean that they are not aligned with the way knowledge is used in the world, nor with its rapid expansion, nor with the current ubiquity of content via desktop and handheld devices. Second, a subject-centered approach yields a deficit model of instructional design, wherein teachers, curriculum designers, textbook producers and test developers identify "gaps" in the learner's knowledge and develop plans to close them. Meanwhile, the "minor" subjects, such as art, music, physical education, which, ironically, are the pathway for many to deeper learning-don't count in contemporary achievement metrics.

Of course, learning must be about something, but the content need not be siloed in "subjects." What if, like Bobby and Allie, we conceived of the classroom as a "think-tank," building the curriculum around problems and questions, not subjects? What if educators approached 
their discipline as a lens for understanding the world, not simply as a body of knowledge to be mastered ${ }^{6}$ Such an approach would help avoid the trap that Whitehead warns against - the mere transmittal of "inert knowledge" (1929, p. 32). As Whitehead insists, and as most educators would agree, what is essential for deeper learning is that the content be transformed or applied in some way (Mehta and Fine 2012). Bobby and Allie's students effect such transformation as they research, analyze, and synthesize their findings about the ways the world might end, and propose preventive measures.

\section{EXPERIENCE AS TEXT}

Paulo Freire (1998) proposes a pedagogy of agency and transformative action in his insistence on action-reflection, the problematization of the existing reality, and, through it all, the reconfiguration of the teacherstudent relationship. There are two basic propositions in Friere's work. First, it is the vocation of human beings to transform the world according to their own purposes. Second, the role of educator is to support the educatee in understanding and acting upon his/her reality. Freire distinguishes between the concrete context-the lived experience of the participants-and the theoretical context, where teachers and students, in the "cultural circle," unpack that reality. It is a method both dialogical and dialectical, yielding cycles of action, reflection, dialogue, and transformation.

Freire's approach to adult literacy, through the cultural circle, is to treat the learners' experience as text. The educator, upon careful study, selects artifacts from the lives of the learners (e.g., a slide projection of a tractor) as "mediating objects" for study and discussion. When learners then see these objects represented as written words, they begin to see that words can speak for them, and that their words and actions, can transform the world. The conviction here is that people's experiences, from which their observations and questions emerge, are "texts" worthy of the same reverence and critical analysis that we give to tangible texts, like books, photographs, paintings, videos, and films. We see something of this approach in the work of Matt Simon and Nuvia Ruland at High Tech High Chula Vista, where students, themselves affected variously in their lives by gun violence, set out after the Sandy Hook massacre in 2012 to make Beyond the Crossfive, a documentary film about gun violence. 
Experience as text takes a central position in internships in the world beyond school. Students in internships-and, with proper support, their teachers-see the world of work and service as a rich context for learning - not only for developing essential skills, but also for extracting critical curriculum content from the student's experience, which serves as a text to be "read," interpreted, and articulated in a multitude of forms. For example, Randy Scherer's 11th grade students at High Tech High Media Arts engage in 3-4-week internships in local business and social service agencies-and publish Ampersand: The Student Journal of School and Work (2015), a record of their various experiences. Scherer's students use a variety of academic and workplace tools and processes to execute and then document their internships-work logs, personal journals, observations, interviews, chronologies, technical manuals, flow charts, project proposals, instructions, letters, reports, storyboards, websites, cameras, and smartphones. They write to reflect on important learning experiences, think through problems, articulate learning goals and project goals, and share experiences with authentic audiences. Writing, often pursued as a decontextualized activity in schools, is here imbued with purpose, as the articulation and communication of personal and academic experience. Through processes of peer critique and multiple drafting, it offers a way, not only to articulate, but also to interrogate, one's experience.

By experience, we mean not only one's lived experience, but also the appurtenances thereto-one's observations, perceptions, values, questions and beliefs - an aggregate of prior life experience, the experience of a current project, and one's experience of external texts. Indeed, we want students reading and analyzing various texts, and we want them to share their experience of those texts, i.e., their observations, analysis, and especially their questions, in seminars or "cultural circles." But if experience is the starting point, where do the "subjects" and canonic texts come into play?

Upon arriving in San Diego to teach, Stephanie Lytle noticed that there were a lot of homeless people in the streets. On learning that many were military veterans, she visited the office of the Veterans Village of San Diego to arrange a project: her students would interview veterans and create a product honoring their service and their lives. Meanwhile, Stephanie's class was reading Beowulf and examining the role of the scop, the bard who sings the praises of returning warriors and who, in the process, functions as a healer. They decided, using the work of Anna Deveare Smith in Twilight, Los Angeles (2003) as a model, that each 
student would compose a poem honoring their partner-veteran, consisting solely of the veteran's words as recorded in the interviews. At the same time, in teaching partner Jeremy Farson's art class, students created paintings to represent their veterans' experiences. In the end, the students invited the veterans to a ceremony at the school, where the students read aloud their poems. They then presented the poems and original paintings to the veterans, one of whom later wrote, "You listened. You didn't judge us. You didn't try to fix us. You listened and you cared. To be listened to and to be heard without being judged, to us was to be honored. Your words and your art have sacred places in our hearts." One of the students wrote, "from 'Hello, my name is...' to the actual reading of the poems, it was no longer a class project. I felt it was almost like my duty to share her story." Lytle adds: "The experience brought home to all of us the enduring power of art and stories, from the time of Beowulf to the present day. As Tim O'Brien writes, 'This too is true. Stories can save us" (Lytle 2010). Indeed, the students were enacting the role of scop, as described in a text written 1000 years before.

Egan (2008) sees the great themes of today persisting in the school of the future, e.g., "nature, society, love, evolution, psychology, and so on..." (71). Postman (1995) suggests five overarching themes as purposive narratives for schools, three of them dealing with themes of equity or sustainability: spaceship earth, the fallen angel, the American experiment, the law of diversity, and the word weavers/world makers. To these, one might add themes of justice, truth, beauty, and fairness, along with the abiding adolescent themes of identity, social relationships, and change. At High Tech High, as students raise and pursue questions, critical societal themes emerge: gun violence, saving the beach, community health and fitness (fifth grade students constructed a parcourse; sixth grade students offered designs via Google Sketch-up for the playground at a new elementary school), species preservation (fourth grade students built and maintained a way-station for Monarch butterflies)—the list goes on and on. ${ }^{7}$ We need not worry about themelessness, and we will not lack for significant content, if we treat young people's experience as a primary text for reflection, articulation, and interrogation.

The challenge- and the art-for teachers is to develop generative questions in such a way as to allow connections between student experience and critical texts in the world. For example, at High Tech High, Jay Vavra and Tom Fehrenbacher's 11th grade students spent an academic year focusing on a single question, e.g., "What is the human impact 
on San Diego Bay?" This question is broad and deep enough to allow a variety of topics, texts, and activities across science, math, English, and history. Art comes into play, too, as Vavra and Fehrenbacher work with students to frame the experience and design ways to share it with the larger community via a field guide and other artifacts of learningilluminated journals, sketches, etc.-in places like the Chula Vista Nature Center, the Maritime Museum, and the San Diego Zoo. Vavra and Fehrenbacher's students are not simply studying science and humanities, but also acting as scientists, historians, artists, editors, and curators.

Experience as text addresses a key question of equity: What gives a child "standing" in the curriculum? Who has the right to speak? Whose experiences are honored and validated? In Bobby and Allie's project, students achieve standing by virtue of the questions that emanate from their experience. Every child has questions; the role of the teacher is to help students connect their questions to each other and to larger questions that are asked in the world beyond school. In effect, Bobby and Allie, and their students, are treating their experience as text, as a way of achieving both equity and excellence. This approach aligns with Freire's (1998) insistence that the role of the educator is to help students both to see their own experiences and perceptions as valid and to learn to critically interrogate them.

The school of the future validates student experience as a starting point and returns to it again and again. As students engage in articulating their experiences, they discover both what is unique about their own experience and what they have in common with diverse peers. Here, we arrive at a deeper reason, both for establishing diverse classrooms and for honoring experience as text: the possibility of constructing together a shared narrative and shared purpose. As Postman (1995, p. 18) reminds us:

Public education does not serve a public. It creates a public....The question is not, Does or doesn't public schooling create a public? The question is, What kind of public does it create?... The right answer depends on two things, and two things alone: the existence of shared narratives and the capacity of such narratives to provide an inspired reason for schooling.

The same applies to culture-if we see the purpose of schooling as culture creation as opposed to culture transmission, we stand a chance of resolving the supposed dichotomy of equity and excellence. 
Treating experience as text offers the additional benefit of attention. Where the default scenario in schools is for the teacher to demand attention to a lecture or external text, experience as text flips the scenario. Now it is the teacher who pays attention to the students-a sine qua non for equitable teaching and learning.

\section{Collegial Pedagogy: Transforming Authority Relations}

The term collegial pedagogy originates in Elisabeth Soep and Vivian Chavez's (2005) work with Youth Radio in the San Francisco Bay area. At Youth Radio, now in its third decade of operation, youth come together outside of school to produce professional-quality programs for National Public Radio and other outlets. Key decisions are made by the students, including what issue to explore, how to go about it, what, ultimately, to say, and how to pitch it to media outlets. It is not Soep who sets standards for the work - she acts as a colleague, not a judge. Instead, because they are engaged in work for an external audience, the students look to the world of work for professional models and develop standards accordingly. They engage in multiple rounds of drafting and critique-processes that one finds in design studios and other professional workplaces. Soep (2008) describes a phenomenon of "swarming," when critique processes have taken hold and become part of the culture of the project. Throughout, the project attends to the expressive needs of adolescents, who emerge as agents whose questions and actions matter in the world. Here, as in the work of Freire, we see a dual transformation: of the teacher-student relationship, and of the relationship to the world. The youth radio project occurs outside of school, in the living community, but it is the kind of work that schools can and should do. The High School for the Recording Arts (HSRA) in St. Paul, MN, a public charter school serving inner city youth, is built along similar premises, as students tap their experiences and explore community issues to create and share professional quality music and art.

At its best, Bobby and Allie's work, and that of their HTH colleagues, exemplifies collegial pedagogy, based in codesign and focused on authentic questions. ${ }^{8}$ They understand that self-directed learning happens in a social context, and that education for equity and sustainability requires a pedagogy that fosters individual and collective agency in doing work that matters. Such a pedagogy calls for a reconfiguration of the authority relations between teacher and students. The traditional bases for 
authority—subject matter expertise, training, age, and salary, however present they may be-are not sufficient. Instead, the authentic basis for authority is to be found in shared purpose and authentic work. The teacher, along with the students, is the custodian of that shared purpose.

We see this pedagogy at work in Bobby and Allie's End of the World project, as students and teachers work together to engage in work incorporating co-design, reflection, dialogue, peer critique, and action. We also see it in Vavra and Fehrenbacher's studies of the San Diego Bay, and in Ruland and Simon's Beyond the Crossfire documentary. We see it in Juli Ruff's (2010a, b) efforts to develop a culture of critique in her classroom. We see it in internships, at High Tech High and elsewhere, where the teacher/advisor serves as facilitator and another adult(s) emerges as mentor. ${ }^{9}$ We see it in Durango, Colorado, where students at Animas High School and Mountain Middle School sprang into action when a leak from the Gold King Mine in Silverton, CO poured toxins into Durango's Animas River. Students went to the river, extracted and tested water samples, visited the site of the mine, consulted with local experts, and presented their findings and recommendations for future management to a local board of geologists, city officials, college students, teachers, and a representative of the Environmental Protection Agency.

Bobby and Allie's work raises questions about teacher expertise. They cannot possibly become expert in all the topics their students are exploring. However, they are expert facilitators who can help students connect with important texts and living resources-and with each other. ${ }^{10}$ Indeed, an important quality for this type of teaching is what Edwards (2007) calls relational agency-the disposition and skill to interact with peers, colleagues, and experts far and wide. If we aspire to foster transformative action on the part of students, we need, as teachers, to model that kind of action as teachers. We also need to re-imagine and re-define key terms in the pedagogical lexicon-e.g., what does "scaffolding" mean in education for agency? In classrooms where outcomes are defined in terms of content mastery, scaffolding aims to control the outcomes. In education for self-directed learning, scaffolding means relinquishing control in order to foster student agency. 


\section{Assessment as Dialogue}

The more any quantitative social indicator (or even some qualitative indicators) is used for social decision-making, the more subject it will be to corruption pressures and the more apt it will be to distort and corrupt the social processes it is intended to monitor.

—Campbell's Law

What will assessment look like in the school of the future? Some, including the developers of the latest round of standardized assessments, ${ }^{11}$ would say we are moving toward ever more sophisticated measures of student understanding, skills, and dispositions-even such qualities as "grit" and "joy." 12 We would argue, with Campbell, that the current approach to assessment, weighted so heavily on quantitative measures, corrupts the processes of teaching and learning. The focus on standardized tests in the USA has atomized the experience of students and teachers, widening the gap between those who have access to deeper learning in schools and those who do not. Moreover, as regards qualities like grit and joy, the testing and test making process tends to put the onus on students for matters that are contextual. As our colleague David Yeager has pointed out in conversation, it is easier and more appropriate to assess students' feelings about what their teachers are doing, and share that information with teachers in the interest of greater teacher effectiveness, than to render students wholly accountable for circumstances that are only partially in their control.

Above all, the school of the future needs to take an integrated approach to assessment, in the recognition that student work, teacher work, and school culture are interdependent. For assessment to have value in guiding learning, it needs to be formative, student-led, and dialogical, with an emphasis on growth and next steps. As such, it needs to be local. It is sheer madness to outsource assessment to distant entities (including machines for scoring), when it is dialogue that is critical to effective, useful assessment. ${ }^{13}$

Briceno (2013), drawing on the work of Farrington et al. (2012, pp. 108-110), discusses four "learning mindsets" as essential to academic success: 
- growth mindset ("I can change my intelligence and abilities through effort")

- self-efficacy ("I can succeed")

- belonging ("I belong in this learning community")

- relevance ("This work has value and purpose for me")

Recognizing the influence of purpose, confidence, effort, and context on student performance, these mindsets suggest a framework for integrated, dialogical assessment that takes teacher work and school culture into account. Is the work authentic (a question that touches on teacher work)? How are individual students developing/not developing qualities of confidence and persistence? How are teachers themselves developing and modeling these qualities? In what ways is the school developing a culture where everyone belongs, and where does it fall short?

Assessment is an everyday process involving reflection, self-assessment, dialogue, peer critique, and revision. In Bobby and Allie's class, the exit card is a typical instrument for daily self-assessment, reflection, and feedback to the teacher. Students may be asked, on an index card, to write one thing they've learned on one side and, on the other, a question for the teacher. The "something learned" may be a content item, or something about a peer, depending on the lesson. Or the questions may be, "What worked for you about today?" and "What could have been better?" The possibilities are endless; the point is that this "assessment" is mutual, offering a window into the student's learning and providing useful feedback to the teacher.

For summative assessments, the more effective and convincing demonstrations of understanding are to be found in work that students have developed over time. At High Tech High and many other schools, students (and staff) maintain digital portfolios of their work. Students give end-of-term "presentations of learning," where they present artifacts of their work to demonstrate and reflect on their learning: ways they've grown, needs, next steps, and longer range plans. Just as Bobby and Allie develop their curriculum from student questions, they also turn the assessment lead over to students. Students address questions about engagement, performance, and purpose: what worked for me in this project or experience? What felt most real and most engaging? What was I most proud of? Where did I encounter problems? Overall, what are my 
strengths and needs? Where's the evidence that I have exhibited growth in one or another High Tech Middle "habits of mind"? What do I need to think about, moving forward? In most cases, students present for about 10 minutes, leaving 20-30 minutes for dialogue, as teachers, parents, and other panelists respond with their own observations, questions, and suggestions.

Some assessment practices at High Tech High are built upon traditional forms, such as the report card and the parent conference. Bobby and Allie bring student reflection and dialogue into these processes via what they call "student-led comments" (followed by teacher responses) and "student-led parent conferences." This approach differs radically from conventional assessment practice, where students complete an assignment or take a test, the teacher assesses whether learning has taken place, and all move on to a new discrete chunk of knowledge to master. And it takes time-time that many teachers would say just isn't available, given the need to "cover" the curriculum. But if we understand assessment as an episode of learning (Wolfe 1992), then it is time well spent.

Authenticity is the linchpin for what Pink (2011) calls intrinsic motivation (see also Deci and Ryan 2008; Deci and Flaste 1996). Traditionally, schools have relied on extrinsic motivators such as grades to push students to persist even when they see the work as irrelevant. If, instead, we succeed in engaging them in work that matters to them (and to the community), we can develop intrinsic motivation. Assessment then becomes a meaningful dialogue driving future learning if students are supported in reflecting on their evolving strengths and areas for growth, on which they then receive feedback and support from their teachers, peers, and parents (For an account of the elimination of grades, where students co-design as assessment of "core growth areas", see Poole 2014).

The "well-being" school asks questions about the intellectual and emotional climate for both students and staff, e.g., via school quality reviews and/or nationally normed climate assessments such as YouthTruth, which explore student perceptions about performance, belonging, adult and peer support, and preparation for the future. Once in possession of such information, the question becomes, what are we going to do about it? The answer: continue to gather information, develop action plans, and act! 


\section{Developing Sustainable Networks for Inquiry and Action}

If we want our schools to be self-renewing entities where diverse students and teachers engage in work that matters, then we need to rethink not only teaching, but also how we support teacher growth within schools.

The evolution of normal schools ${ }^{14}$ into university-based teacher training programs in the late 1800 s, motivated by a desire to improve and standardize teaching (Harper 1939), brought with it a distinct separation between teacher education and the life of schools. Young women and men studied the subjects they would teach and were then thrust into schoolhouses to toil in isolation, with little to no teaching experience. Unlike the apprenticeship model common to many vocations, where learning happened on the job alongside a master (Smith 1998), the teacher's "education" was presumed to have ended by the time they entered the classroom.

Not much has changed since then. The typical teacher in the USA completes a university degree in education or a particular discipline and then goes on to earn a teaching credential, engaging in as little as two weeks of student teaching alongside a veteran teacher. Once hired, most new teachers discover that their schools provide little in the way of professional development or opportunities for collaboration. Occasional faculty meetings tend to focus on logistics, student support or discipline-specific planning rather than matters of instructional design or pedagogy. Teachers who wish to develop their practice are encouraged to enroll in programs of study beyond the school, thus reifying the boundaries between theory and practice. ${ }^{15}$

In this way, most schools in the USA fall solidly on the "buy it" side of what some reformers have characterized as the "build it or buy it" debate (Green 2014; Mehta and Fine, in press). As a society, we invest the bulk of our time, energy and resources in preparing teachers to enter the profession, expending very little to ensure they continue to grow as teachers and stay in the profession.

In contrast, the future school orients itself toward the "build it" side of the debate, investing significant resources and energy in supporting teachers after they have arrived. At High Tech High, for example, we place great emphasis on hiring teachers who share our commitment to serving diverse students in an integrated, project-based environment. ${ }^{16}$ We seek individuals who want to know what and how students think, 
and who are ready and willing to collaborate with colleagues. However, bringing in good people is only the first step.

\section{Designing Significant Learning Experiences for Adults}

Adults - and young people-learn by doing, by engaging in work that is challenging and purposeful, and through social interaction, particularly in apprenticeship with more experienced members (Dewey 1938; Lave and Wenger 1991; Smith 1998; Rogoff et al. 2001). If teachers are to "learn by doing," it is up to schools to design "educative experiences" (Dewey 1938) for them, like the ones the teachers will design for students.

New teachers at High Tech High enter a community of inquiry that values their prior experiences and their emerging questions. Whether fresh out of a credential program, transitioning from industry, or having several years of teaching experience, they all participate in an eightday Odyssey before school opens, which offers an immersion in HTH design principles and pedagogy. On the first day, teachers begin a twoday "Project Slice" where they experience a transdisciplinary project as a learner. Recent "slices" have included explorations of the nearby US/ Mexico border, designing and building interactive toys for an orphanage in Mexico, and studying the flora and fauna of San Diego Bay. In each case, teachers do what they will later be asking their students to do: generate questions to pursue, conduct fieldwork in the community, and collaborate to create a product to exhibit, which they prototype and take through multiple rounds of critique and revision.

Throughout the Odyssey, we build in time for teachers to reflect and make meaning of this experience, identifying and unpacking the structures and pedagogical moves that have facilitated their learning. Where did they experience choice and voice? How did the instructional design and facilitation provide access and challenge for different learners? What was communicated about what HTH values? We also ask everyone to share a moment of "significant learning" from their own K-12 years and, in groups, extract from those stories the elements of significant learning. The elements are predictable: meaningful mentorship, challenge, risk, teamwork, an important audience, connection to a passion or authentic question, someone who believed in them, etc. ${ }^{17}$ We can then ask, "What would a place look like where significant learning was going on all the time?" 
This constant toggling back and forth between experience and reflection serves as an introduction to a pedagogy that values experience as grist for future learning. In Experience and Education (1938), Dewey argued that in order for reflection to be educative-that is, to facilitate future learning and decision-making-it must be rooted in experience. This is true for both youth and adults. Too often in schools, students and teachers are asked to reflect on situations and issues disconnected from their daily lives, to engage with abstractions rather than their own experience. By creating rich learning experiences for teachers that can then serve as touchstones for the experiences they create for their own students, the future school enacts a powerful symmetry of practice; the adults learn as we hope the students will.

This symmetry persists in Odyssey activities that nurture collegial pedagogy and challenge traditional hierarchies in schools. Before teachers design their first project, they participate in "project tuning" or "looking at student work" sessions, where a veteran teacher brings a draft project design or samples of student work, and asks for advice. In small groups, often involving K-12 students as well, ${ }^{18}$ the new teachers follow a protocol to ask clarifying and probing questions and engage in dialogue about the work. This exercise communicates to new teachers that their perspectives matter, that as teachers we make our work and thinking public, and that we are all still learning. Moreover, by helping veteran teachers think through their questions, grounded in artifacts of teaching and learning, the new teachers identify criteria for quality work that will guide their own project designs over the week and beyond. They complete the Odyssey by giving a formal Presentation of Learning (POL), where they share their project designs and ongoing questions with peers and veteran teachers, thereby experiencing a process they will facilitate for their own students during the year.

The Odyssey serves as an introduction to the routines and rituals that undergird teacher life at HTH. Teacher collaboration is at the heart of the work-and we know that effective collaboration doesn't just happen. Instead, we do our best to "shape the path" (Heath and Heath 2011) by providing purposeful structures and protocols, ${ }^{19}$ like the ones referenced above, that ensure all voices are heard, encourage divergent ideas, and keep conversations focused and productive. Each protocol concludes with a debrief: how the process worked, how it could be better, what "moves" the facilitator made that helped or stymied the conversation. In this way, protocols help the adults in a school hold productive 
conversations and grow as facilitators of each other's learning. The more often educators engage in protocols, the more likely they are to use them with students. They may conduct a project tuning with students to elicit their ideas about an upcoming project, or have students use protocols to give each other feedback on drafts of their work or to talk through a dilemma.

While protocols have emerged as essential tools at High Tech High, they are not a magic bullet. If they are treated as a series of steps to plod through, or if participants fail to move past niceties and offer each other kind, helpful and specific critique (Berger 2003), the ensuing conversations can feel superficial and even frustrating. However, when the purpose is clear and aligned to the school's values, and when the community establishes clear norms for interaction, they can catalyze collaboration, dialogue and reflective practice. They honor the questions that arise from teachers' practice-a lesson gone wrong, a puzzling interaction, an idea for a project-in short, a "wondering they wish to pursue" (Hubbard and Power 1999).

\section{Developing Communities of InQuiry and Action}

What are my dreams for our school, for my students?

How do I want to grow over the next year?

If equity is at our core, what areas - in my practice and our school - are ripe for improvement?

Just as Bobby and Allie's students rush in from recess to discover a provocative prompt on the board, the teachers at High Tech Elementary Chula Vista $(\mathrm{HTeCV})$, arrive to their afternoon professional development session to discover the journal prompts above. The school is a few miles from the Mexican border; teachers can see the mountain ranges of eastern Tijuana from the classroom. It's no mistake that the first question is about their dreams. Sharing their dreams for students, and the ways in which they hope to grow in the coming year, is a first step in identifying areas for improvement. As with Bobby and Allie's students, several themes emerge. Teachers want to ensure all students are able to read and write well, articulate their thinking to others verbally and visually, participate equitably in group work, see themselves as mathematicians, persevere through challenges, resolve conflicts independently, and feel a deep sense of belonging to the school community. They want to 
ensure their assessments are equitable and student-centered, and that their projects elicit deeper learning. All of these topics are worthy of inquiry and action, and all are rooted in teacher's aspirations for a more equitable and engaging learning environment.

The following week the faculty reconvenes to determine which topics will drive improvement groups, where teachers will work together for the rest of the year to dig into the problems they want to solve, set a goal for what they want to achieve, and enact "change ideas" in their classrooms in pursuit of that goal. Teachers choose from the themes synthesized from their own reflections, along with topics other HTH schools are working on already. They vote for the topics they feel are most likely to advance issues of equity, and those they are most inspired to explore. In the end, four groups emerge: Making Thinking Visible, Equitable Group Work, Student Agency, and Improving Writing Instruction. Three of these topics are already being pursued by other HTH schools, so there is opportunity for sharing ideas and learning across campuses, grade levels and disciplines. The energy is high. There are spontaneous high fives. Now the real work begins.

Over the course of several afternoon sessions, in a process initially guided by HTH GSE faculty, the teacher teams dig into their issues and develop a theory of action for moving forward. Using a protocol, they construct a fishbone diagram to unpack the root causes influencing their problem: What makes it hard for all students to participate meaningfully and equitably in group work? What affects students' abilities to persevere through challenges? Why is it difficult for students to share their thinking with the class? What makes writing challenging, and why, at such a young age, do some students already feel they are writers and others have decided they are not? Each teacher will conduct an "empathy interview" with at least one student, so that the group will have tapped into multiple perspectives on the issue. They will refine their fishbone diagrams and construct a clear and measureable aim for their project (see Fig. 4.2). And they will use another protocol to construct a Driver Diagram that articulates areas of focus and concrete change ideas they want to implement.

Moving forward, improvement groups meet every week for an hour to share the change ideas they are trying in their classrooms, analyze the data they have gathered, and plan next steps. They collect and analyze video clips of students working in groups, exit cards and short surveys, teacher observations, empathy interviews with students or samples of student work. They use a structure called a PDSA (plan-do-study-act) 
Title: Improving Groupwork in STEM

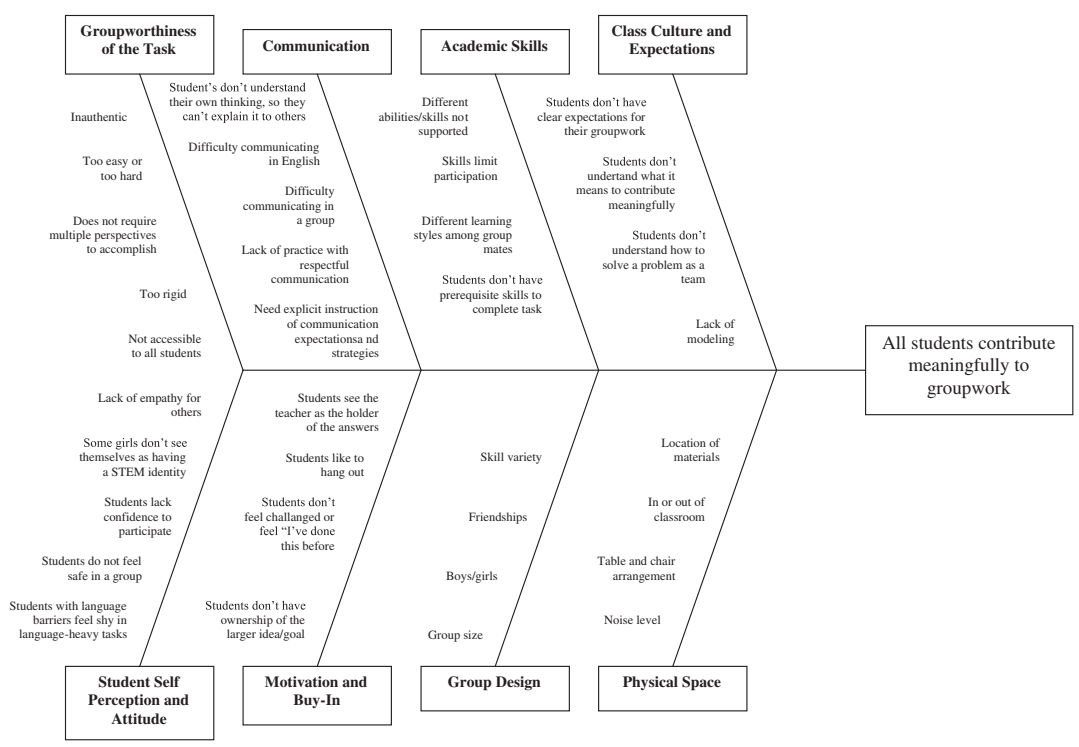

HTeCV Improvement Research Team, 2015-2016

Fig. 4.2 Fishbone diagram for equitable group work

cycle (Langley et al. 2009) to capture their learning and guide short cycles of inquiry, action, and reflection.

Several weeks into this work, $\mathrm{HTeCV}$ hosts 25 principals from the New Tech Network, ${ }^{20}$ who want to learn about how improvement science works at the school. They listen as teachers and students describe how the work has affected teaching and learning in the school. They help gather data for two teachers working on their latest PDSA cycle regarding equitable group work, and offer suggestions for improvement.

Three 4th graders, introduced as research collaborators in the equitable group work team, share ideas their class generated to help more students participate meaningfully in group work, and how their own behavior was affected by viewing videos of their groups working together. One boy shares, "Seeing the video made me realize that I was not great about sharing the air, so I set a goal for myself to talk less and invite others in." A girl shares that seeing the video "made me realize that I was off task a lot more than I thought. Since then, I've tried 
harder to not distract others." Both report that they could see in subsequent videos that they were improving toward their goals.

These same students facilitate the debrief at the end of the day, where the visiting principals share what struck them from the visit, what questions arose, and what implications they see for their own work. At one point, one of the 4th grade facilitators looks at an adult who hasn't spoken yet and says, "Miss Megan, I've noticed that you haven't said anything yet. Would you like to?"21

The last question from one of the visiting principals is, "How can I get this to happen in my school?"

The simple answer is that this can happen in many ways, with many different starting points. However, it always begins with questions that are triggered by the context, and a desire to address problems in the system that lead to inequitable outcomes or detract from the student experience. For example, at High Tech High North County (HTHNC), the Director wondered why his school was among the lowest in the organization for the percentage of students applying and ultimately attending four-year colleges. ${ }^{22}$ In a school committed to ensuring all students are ready for college, career and civic life, this posed an equity dilemma for him. If more of his students, especially low-income students, were to get to four-year college and succeed there, they would have to apply. That was the first hurdle.

To explore that hurdle, the director applied to college himself. He discovered that it was much more confusing than he had assumed. As a result, he worked alongside his college counselor and the teaching faculty to implement a menu of interventions, embedding application support into the advisory program, offering workshops during lunch and after school, and inviting seniors to sit alongside their advisors during a staff day and literally complete and submit college applications (see Driver Diagram, Fig. 4.3).

Along the way, the faculty conducted empathy interviews and focus groups with students to understand the challenges they faced in applying and going to college, and surveyed all seniors to figure out which interventions students found most helpful. Upon learning that the personal statement was an obstacle for many students, they decided to embed support for writing it into 11th grade Humanities classes. After two years of concerted effort, HTHNC has increased the percentage of students applying to four-year colleges from $90 \%$ in 2015 to $98 \%$ for 2016 . Within the past three years, they have gone from having the lowest to 
HTHNC College Application Process

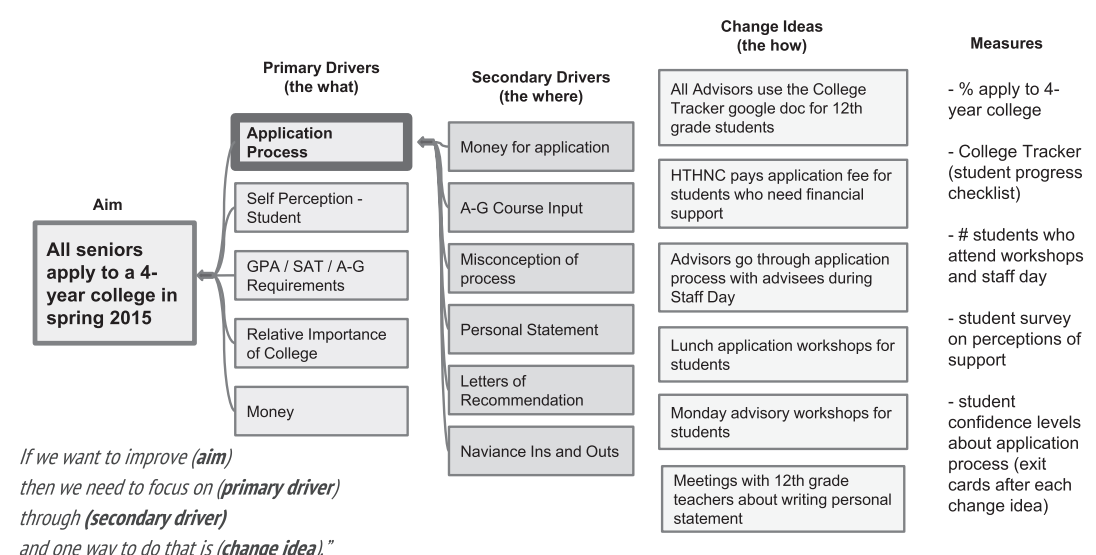

Fig. 4.3 HTHNC driver diagram

the highest percentage of students who apply - and who actually go-to four-year colleges in our organization (Jones et al. 2015) (see Fig. 4.4).

In the vignettes above, the school directors co-designed the improvement efforts with teacher leaders from their schools and faculty from the HTH Graduate School of Education (GSE). The topics that ultimately drove the work emerged from faculty's dreams and concerns, and were grounded in a shared desire for deeper learning and equitable outcomes. And the first step was to involve and learn from students. At HTeCV, students as young as first grade are engaged as co-researchers coming up with change ideas, collecting and analyzing data, and planning next steps. Lacy Szulwalski, a School Leadership resident pursuing her Masters degree through the HTH GSE, set a goal for HTeCV to reduce waste and increase recycling. She worked with students and teachers to conduct a series of waste and recycling audits as they tried out different interventions, and eventually launched a student-led school-wide campaign called My Actions Matter, which culminated in a studentillustrated children's book (Szuwalski 2015).

In a non-High Tech High environment, Ashley Vasquez, a second grade teacher at the Finney Elementary School in Chula Vista and M.Ed. student at the GSE, engaged her students in a series of service learning projects, hoping to demonstrate that young children could make 


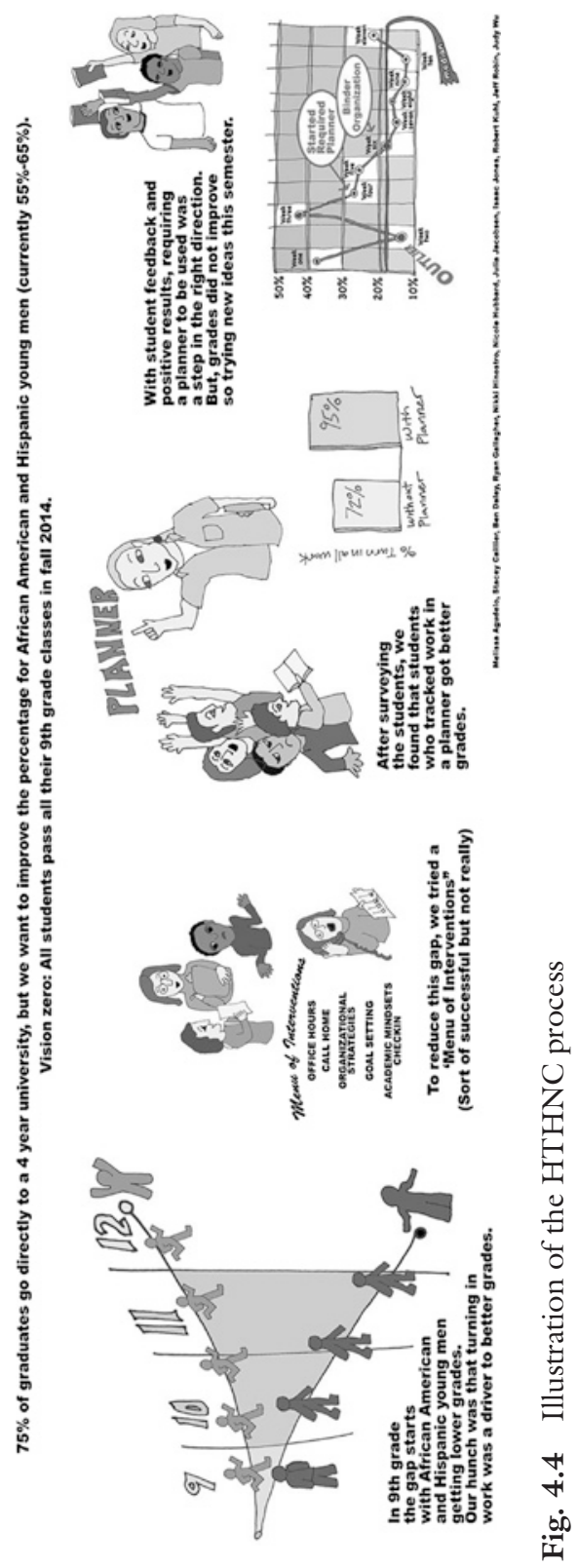


meaningful contributions to their community (Vasquez 2012). Working in collaboration with the local fire department and children's hospital, her students designed a fire safety campaign for local families and organized a toy drive for children in the cancer ward. She found that these opportunities increased the frequency and quality of peer collaboration and engagement in the classroom, and bolstered students' belief that they could be "change makers" in their predominantly Latino, low-income community. She also discovered that this work led to increased writing proficiency and fluency because students were eager to reflect on what they were learning and make their writing as polished as possible for an external audience. In short, they saw the relevance of their work beyond the classroom.

Whether teachers are working in more homogeneous schools, like Ashley's, or in schools that are diverse and integrated by design, like $\mathrm{HTH}$, questions of equity are at the core of meaningful school change. The good news is that such questions emerge naturally in schools all the time. The bad news is that they are usually pushed aside. The task of the future school is to embrace these questions and support educators, students and communities in grappling with them. We have found the following guidelines helpful in organizing our work, and propose them as useful for the future school as well:

- Excavate. Support educators and students in critically examining their own beliefs, practices, and the systems in which they live and work..$^{23}$

- Disrupt. Use disciplined inquiry to disrupt predictable patterns of success and failure, and the inequitable practices that perpetuate them.

- Design. Engage colleagues, students, and communities in designing strategies and transforming systems to create more equitable, engaging learning environments for young people and adults.

We have found improvement science (IS) to be a promising framework for scaffolding and focusing this work, particularly as our network of schools has grown. ${ }^{24}$ Building upon other forms of practitioner research-such as action research and design-based research-IS assumes practitioners, as insiders, are in a unique and powerful position to both contribute to the knowledge base and use that knowledge to improve teaching and learning (Caillier 2008). It resituates educators and young 
people as the designers of change efforts, not simply the beneficiaries or implementers of others' ideas. At its best, it cultivates the dispositions we are after: the impulse to learn with and from students, to ground our reflections and next steps in evidence of student learning and engagement, to engage in reflective conversations with colleagues, and to look to existing research and craft knowledge to identify best practices and adapt them for our own contexts.

At the core of this work are three questions (Langley et al. 2009): What is our goal? How will we know if we've met our goal? What innovations can we introduce into the system that might lead to meeting that goal? The questions are simple, yet profound. Most educators have no shortage of ideas, and are constantly reflecting on their practice and making adaptations that they hope will better serve students (i.e. the third question). However, we don't always take the time to set a clear, measureable goal and identify how we will know if we are making progress toward it, let alone develop systematic ways for tracking progress. The future school, in its attention to coherence and shared purpose, attends to all three questions and creates structures within the school day for teachers to engage in this work.

Since our inception, we have been committed to teacher inquiry, and interested in how knowledge from such inquiry spreads. We have discovered, not surprisingly, that the degree to which teacher learning and effective practices spread is largely dependent on the social capital, or individual relational agency and influence, of the people involved in the inquiry (Moolenar et al. 2014). In addition, as we have grown, we have recognized significant variation in relation to core practices that support a deeper learning pedagogy, such as peer critique, presentations of learning, assessment for growth, equitable group work, project design, and collegial coaching. All of this necessitates that we find effective ways to act collectively, to ground educators in our organization's values and aspirations from the beginning and help them learn from each other. ${ }^{25}$ The goal for the future school as a sustainable community of inquiry is, as Deming (1986) has said, "to improve constantly and forever". ${ }^{26}$

\section{Conclusion: It Starts with the Adults}

We have proposed to blow up the schedule, change the subject, tear down the walls, and recast the role of teachers. We have proposed that schools treat experience as text, engage in collegial pedagogy, connect with the 
community, and conduct assessment as a dialogue, recognizing in each of these domains the interdependency of the learner and the learning environment. We would situate teachers as researchers, challenging current hierarchical notions of knowledge about teaching and learningwhat it is, and who creates it. Recognizing that classrooms and schools are dynamic systems, we have suggested possible design principles rather than a fixed model, and have insisted on assessment as integrated and dialogical, focusing on the quality of learning, the quality of life, and the health of the organization.

Tapping the enormous capacity of teachers and students, the future school integrates theory and practice, engaging in cycles of reflection, inquiry, and action to address questions of equity and sustainability. It prepares individuals to work on those issues throughout their lives in a multitude of contexts. In the end, practitioners and students come to see school itself as a project, aimed at the transformation of self, school, and society.

Taken together, these notions represent a substantial paradigm shift, yet there is nothing new in the particulars. Approaches such as Socratic seminars, apprenticeship models, inquiry-based learning, field work, maker spaces, creative distance learning, service learning, and teacher research are going on all over the world. But too often, these activities happen at the margins of the educational landscape-in particular classrooms, in after-school programs, or as "enrichment," unconnected to a broader enterprise or larger purpose.

We argue for the centrality of these activities - that they should move from the margin to the mainstream. Much of the current "reform" movement, even in newly created schools, is parked within conventional structures, subjects, and assessments. Still, there are grounds for optimism. The experiences of places like Trigg County, Kentucky, ChiTech Academy in Chicago, the internship-based schools founded by Big Picture Learning, and the High School of Recording Arts (HSRA) in St. Paul, Minnesota, to name just a few, indicate that a transformation is well underway in a variety of communities and contexts. The revolt against relentless standardized testing offers similar grounds for hope (Abeles 2015).

One thing is certain - there will be no transformation without changing the conditions of work for teachers, whose role is vitally important and widely ignored. In the future school as we imagine it, adult learning mirrors student learning, as teachers and students co-design projects of 
lasting value that transcend disciplinary and spatial boundaries. Teachers engage in collaborative lesson design, share dilemmas of practice, examine student work together, and engage in collective inquiry and action. The latter is particularly important because it equips teachers-and organizations - to adapt to a changing environment. It addresses the issue of sustainability for innovative schools, building the kind of culture that can survive the departure of visionary, charismatic leadership.

Education is, and has always been, cultural action, for better or worse. And the context has too often been one where policy makers and communities have acted to constrain school culture-to narrow the available options and limit teacher autonomy and agency. As documented in the film, Most Likely to Succeed, the current structures, curriculum, pedagogy and assessment emanate from the needs and assumptions of industrial society, for which they are well suited. They are not well suited, however, for the global information age.

Subject matter silos, standardized testing, alienation from the community, and the disconnect between theory and practice have generated a perfect storm of irrelevancy in our schools. Where they ought to unleash energy, schools tend to constrain. The principles for a sustainable school fly in the face of our test-saturated culture, offering an alternative vision of what matters-not performance on standardized tests, but the purposeful interactions between people in diverse environments and the quality and authenticity of the work they are engaged in.

Public schools, whatever their shortcomings, remain the linchpin of social cohesion- the one place where individuals from all walks of liferich or poor, urban or rural, male or female, all races and ethnicities, all religions, all sexual orientations, all talents and abilities-come together. As such, schools have a responsibility to serve all students and to serve the greater good, and to pursue questions attendant to those purposes.

Even the most equitable schools cannot themselves resolve the large issues we face, but they can model shared vision and collective action. As micro-societies, they can enact personal empowerment, democratic processes, design thinking, an emphasis on production as opposed to mere consumption, a focus on sustainability, connections to community, and the development of human and social capital. Both by example and by their action in the world-and by their determination to sustain and renew themselves as equitable communities of inquiry - they can play a critical role in the transition to a sustainable well-being society. 


\section{Notes}

1. For footage of an exhibition night at High Tech High, see the documentary film, Most Likely To Succeed, accessible for community viewing via http://mltsfilm.org/.

2. For an overview of research activities at the High Tech High Graduate School of Education, visit https://hthgse.edu/crei/overview/.

3. Paul Batalden is the original source of this comment, a variation on Arthur Jones's remark, "All organizations are perfectly designed to get the results they get," quoted in Hanna (1988, p. 36).

4. The aim is to develop schools and classrooms that are intentionally integrated across a range of ethnicities, identities, social class backgrounds, and life experiences-and to demonstrate that in such an environment everyone benefits and no one is harmed. Residential segregation in San Diego County is so prevalent that postal codes are a reliable proxy for race, ethnicity, and social class. Of the 5158 students in HTH schools in 2016, 31\% are Caucasian, $41 \%$ Hispanic, 9\% African-American, $12 \%$ Asian, 2\% Pacific Islander, and 4\% Native American; 46\% qualify for free or reduced lunch, $13 \%$ are on special education plans, and $8 \%$ are classified as English learners.

5. We distinguish between personalized learning, where students exercise voice and choice and pursue their questions and passions, and individualized instruction, where the teacher, or computer program, engages in a process of diagnosis and prescription for students working alone.

6. See Riordan and Rosenstock (2013) for a brief exploration of possible projects that integrate the disciplines in this way.

7. See the High Tech High website at hightechhigh.org/projects for descriptions of hundreds of projects. See also the digital portfolios for each HTH teacher, also available at www.hightechhigh.org under K-12 Schools.

8. Notably, it is student questions, not student interests, that inspire the curriculum. With interests, students and teacher gravitate toward what they already know; with questions, they gravitate toward what they don't.

9. For a student account of the transformative power of internships, see Del Rosario (2015).

10. For a practical discussion of equitable group work in heterogeneous settings, see Cohen and Lotan (2014).

11. For an overview, see Ravitch, D. (2016). Solving the mystery of the schools. New York Review of Books, LXIII, 5, March 24, 2016, 34-36.

12. Zernike, K. (2016). Testing for Joy and Grit? Schools Nationwide Push to Measure Students' Emotional Skills. New York Times, February 29, 2016. 
13. There remains the question of assessment for purposes of making public policy. Here, given the way that testing disrupts and distorts the learning process, simple structures are best. The sampling methods embedded in the National Assessment of Educational Process are sufficient for policy-making purposes.

14. Normal schools emerged in the 1830 s as a teacher training ground for women, who were largely excluded from male preparatory academies. Prior to this time, teaching was a largely male profession where anyone with passable literacy was allowed to teach (Harper 1939).

15. There is ample criticism of virtually all aspects of current teacher training and development, including the disconnect between theory and practice as reified in the school-university divide, in-school hierarchies (new vs. veteran teachers, vocational vs. academic teachers), the hegemony/exclusivity of subject-oriented teaching, the dearth of innovative clinical sites, and inadequate or non-existent provision for teacher growth in schools. See, for example, Sarason (1993), Levine (2006), Sizer (2008), and Mehta and Schwartz (2014).

16. At HTH, prospective hires go through a rigorous "Bonanza" where they spend a full day teaching demo lessons, interviewing with faculty and students, engaging in group discussions of provocative texts that surface important issues of equity and social justice, and collaboratively designing an interdisciplinary project for an authentic audience. Throughout this process, we look for evidence of the dispositions we care about - an eagerness to ask questions, listen to students, collaborate with colleagues, reflect on their own experience and work, tolerate ambiguity, and overturn traditional power structures in the classroom.

17. Not surprisingly, many of the moments people describe happen outside of school and in less formal environments in the outdoors, in clubs, or on sports teams.

18. See Krueger (2014) for an account of 6th graders' participation in professional development activities.

19. The use of protocols builds on a legacy of progressive education embodied by Ted Sizer's Coalition of Essential Schools. MacDonald (2007) and the School Reform Initiative (http://www.schoolreforminitiative.org) are rich repositories of wisdom and protocols for all occasions.

20. The New Tech Network, along with High Tech High and several other organizations, is part of the Hewlett-funded Deeper Learning Network, which includes over 500 schools in the USA, serving over 227,000 students.

21. The student comments reported here come from a range of students, from middle class to low-income, white to Hispanic, all of whom have internalized the norms for effective group work and are capable of guiding adult conversation. 
22. This was particularly troubling given that in $\mathrm{CA}$, one in 10 kindergarteners from a low-income family will actually earn a 4-year degree (DarlingHammond 2010), and only $13 \%$ of low-income students who begin at a 2 -year college will earn a 4-year degree within 6 years (Cahalan and Perna 2015).

23. At the Deeper Learning 2015 conference in San Diego, Dr. Chris Emden of Teachers College, Columbia University and Director of Science Education at the Center for Health Equity and Urban Science Education, spoke passionately about the need for teachers to excavate, or unpack and critically examine, the manner in which they engage with students and the ways in which their own assumptions, experiences and bias perpetuate inequities in the schooling system. He argued for a "reality pedagogy," which empowers students to engage in this excavation alongside teachers, so that together they can construct learning environments where all voices are heard, all experiences are honored and knowledge is co-constructed. For a discussion of particular strategies Chris identified that teachers can use, see this blog post from a participant: http://ghsinnovationlab.com/2015/04/02/deeper-learning-2015-day-1/.

24. About 165 (28\%) HTH staff, including directors, teachers, site managers, college counselors, etc. are actively engaged in improvement work. For those interested in learning more about improvement research in education, we recommend Bryk, Gomez, Grunow and LeMahieu's book, Learning to Improve: How America's schools can get better at getting better (2015).

25. For discussions of why improvement science is particularly well-suited for taking innovations to scale and creating knowledge that will work across multiple contexts, see Silva and White (2013), and Bryk et al. (2011). For discussions of how improvement science challenges traditional approaches to educational research and educational reform, see Jones et al. (2015), Donovan (2013), Gutiérrez and Penuel (2014).

26. Readers may access tools and protocols for engaging in improvement work here: https://hthgse.edu/crei/protocols/.

\section{REFERENCES}

Abeles, V. (2015). Beyond Measure: Rescuing an Overscheduled, Overtested, Underestimated Generation. New York: Simon \& Schuster.

Ampersand: The Student Journal of School and Work. (2015). Retrieved February 27, 2016, from http://www.amazon.com/Ampersand-Student-Journal-SchoolSeven $/ \mathrm{dp} / 1514749785 / \mathrm{ref}=\mathrm{sr}_{-} \mathrm{l}_{-} \mathrm{l}$ ? s=books\&ie $=\mathrm{UTF} 8 \& \mathrm{qid}=$ $1456603964 \& s r=1-1 \&$ keywords $=$ Ampersand + the + Student + Journal. 
Berger, R. (2003). An Ethic of Excellence: Building a Culture of Craftsmanship with Students. Portsmouth, NH: Heinemann.

Briceno, E. (2013). Mindsets and Student Agency. UnBoxed, (10). Retrieved July 5, 2018, from http://gse.hightechhigh.org/unboxed/issue10/mindsets_and_ student_agency_contributors/.

Bryk, A. S., Gomez, L. M., \& Grunow, A. (2011). Getting Ideas into Action: Building Networked Improvement Communities in Education. In M. T. Hallinan (Ed.), Frontiers in Sociology of Education (pp. 127-162). The Netherlands: Springer.

Bryk, A. S., Gomez, L. M., Grunow, A., \& LeMahieu, P. (2015). Learning to Improve: How America's Schools Can Get Better at Getting Better. Cambridge, MA: Harvard Education Press.

Cahalan, M., \& Perna, L. (2015). Indicators of Higher Education Equity in the United States. Washington, DC: Pell Institute and Penn AHEAD.

Caillier, S. (2008). Transforming Schools One Question at a Time. UnBoxed, (1). Retrieved July 5, 2018, from http://gse.hightechhigh.org/unboxed/ issuel/transforming_schools/.

Cohen, E., \& Lotan, R. (2014). Designing Groupwork: Strategies for the Heterogeneous Classroom (3rd ed.). New York: Teachers College Press.

Darling-Hammond, L. (2010). The Flat World and Education: How America's Commitment to Equity Will Determine Our Future. New York: Teachers College Press.

Deci, E., \& Flaste, R. (1996). Why We Do What We Do. New York: Penguin Books.

Deci, E., \& Ryan, R. (2008). Self-Determination Theory: A Macrotheory of Human Motivation, Development, and Health. Canadian Psychology, 49(3), $182-185$.

Del Rosario, L. (2015). My Education at the Met. UnBoxed, (13). Retrieved July 5, 2018, from http://gse.hightechhigh.org/unboxed/issuel3/my_ education_at_the_met/.

Deming, W. E. (1986). Out of the Crisis. Cambridge, MA: MIT Press.

Dewey, J. (1938/1997). Experience and Education. New York: Simon \& Schuster Touchstone Edition.

Donovan, M. S. (2013). Generating Improvement Through Research and Development in Education Systems. Science, 340(6130), 317-319.

Edwards, A. (2007). Relational Agency in Professional Practice: A CHAT Analysis. Actio: An International Journal of Human Activity Theory, 1, 1-17.

Egan, K. (2008). The Future of Education: Reimagining Our Schools from the Ground Up. New Haven: Yale University Press.

Farrington, C., Roderick, M., Allensworth, E., Nagaoka, J., Keyes, T. S., Johnson, D. W., et al. (2012). Teaching Adolescents to Become Learners. The Role of Noncognitive Factors in Shaping School Performance: A Critical 
Literature Review. Chicago: University of Chicago Consortium on Chicago School Research.

Fehrenbacher, T. (2015). Logs from San Diego Bay. UnBoxed, (13). Retrieved July 5, 2018, from http://gse.hightechhigh.org/unboxed/issuel3/logs_from_ san_diego_bay/.

Freire, P. (1970/1998). Cultural Action for Freedom. Reprinted in Harvard Educational Review, 68(4), 476-522.

Green, E. (2014). Building a Better Teacher: How Teaching Works (And How to Teach it to Everyone). New York: W.W. Norton.

Gutiérrez, K. D., \& Penuel, W. R. (2014). Relevance to Practice as a Criterion for Rigor. Educational Researcher, 43(1), 19-23.

Hämäläinen, T. (2014). In Search of Coherence: Sketching a Theory of Sustainable Well-Being. In T. Hämäläinen \& J. Michaelson (Eds.), Wellbeing and Beyond: Broadening the Public and Policy Discourse. Cheltenham: Edward Elgar.

Hanna, D. (1988). Designing Organizations for High Performance. Upper Saddle River, NJ: FT Press.

Harper, C. A. (1939). A Century of Public Teacher Education: The Story of the State Teachers Colleges as They Evolved from the Normal Schools. Washington, DC: Hugh Birch-Horace Mann Fund for the American Association of Teachers Colleges.

Heath, C., \& Heath, D. (2011). Switch: How to Change Things When Change Is Hard. New York: Random House.

Hubbard, R., \& Power, B. (1999). Living the Questions: A Guide for TeacherResearchers. Portland, ME: Stenhouse Publishers.

Jones, I. et al. (2015). Getting More Students to College: A Foray into Improvement Research. UnBoxed, (13). Retrieved July 5, 2018, from http:// gse.hightechhigh.org/unboxed/issuel3/a_foray_into_improvement_science/.

Krueger, B. (2014). Students as Experts in Professional Development. UnBoxed, (11). Retrieved July 5, 2018, from http://gse.hightechhigh.org/unboxed/ issuel1/students_as_experts_in_professional_development/.

Langley, G. et al. (2009). The Improvement Guide: A Practical Approach To Enhancing Organizational Performance. San Francisco, CA: Wiley.

Lave, J., \& Wenger, E. (1991). Situated Learning: Legitimate Peripheral Participation. New York: Teachers College Press.

Levine, A. (2006). Educating School Teachers. Washington: The Education Schools Project.

Lytle, S. (2010). Voices and Visions. UnBoxed, (6). Retrieved July 5, 2018 from http://gse.hightechhigh.org/unboxed/issue6/voices_and_visions/.

McDonald, J., et al. (2007). The Power of Protocols: An Educator's Guide to Better Practice (2nd ed.). New York: Teachers College Press.

Mehta, J., \& Fine, S. (2012, October). Teaching Differently ... Learning Deeply. Phi Delta Kappan, 94(2), 31-35. 
Mehta, J., \& Fine, S. M. (in press). In Search of Deeper Learning: Inside the Quest to Remake the American High School. Cambridge, MA: Harvard University Press.

Mehta, J., \& Schwartz, R. (2014). Building a Twenty First Century School System: Creating a Teaching Profession and Multiple Student Pathways. In Kathleen McCartney, et al. (Eds.), Improving the Odds for America's Children: Future Directions in Policy and Practice. Cambridge: Harvard Education Press.

Moolenaar, N. M., Daly, A. J., Cornelissen, F., Liou, Y.-H., Caillier, S., Riordan, R., et al. (2014). Linked to Innovation: Shaping an Innovative Climate Through Network Intentionality and Educators' Social Network Position. Journal of Educational Change, 15(2), 99-123.

Oakes, J. (1985). Keeping Track: How Schools Structure Inequality (2nd ed.). New Haven, CT: Yale University Press.

Orfield, G. (2009). The Long Road: (Re)Segregation in America. UnBoxed, (3).

Pink, D. (2011). Drive: The Surprising Truth About What Motivates Us. New York: Riverhead Books.

Poole, M. (2014). Assessment in Core Growth Areas: An Exploration into Replacing Grades. Master's thesis. Retrieved April 3, 2016, from http:// markpoolesdp.weebly.com/complete-thesis.html.

Postman, N. (1995). The End of Education: Redefining the Value of School. New York: Alfred A. Knopf.

Riordan, R., \& Rosenstock, L. (2013). Changing the Subject. Monograph. Retrieved February 12, 2016, from http://gse.hightechhigh.org/.

Rogoff, B., Goodman Turkanis, C., \& Bartlett, L. (2001). Learning Together: Children and Adults in a School Community. New York: Oxford University Press.

Ruff, J. (2010a). Collaboration, Critique, and Classroom Culture. UnBoxed, (6). Retrieved July 5, 2018, from http://gse.hightechhigh.org/unboxed/issue6/ collaboration/.

Ruff, J. (2010b). Peer Collaboration and Critique: Using Student Voices to Improve Student Work. Retrieved December 6, 2013, from http://dp.hightechhigh.org/\%7Ejruff/GSE/understands2.html.

Sarason, S. (1982). The Culture of the School and the Problem of Change. Boston: Allyn and Bacon.

Sarason, S. (1993). The Case for Change: Rethinking the Preparation of Educators. San Francisco: Jossey-Bass.

Shaddox, B. (2013). Co-design: A Democratic Approach to Project-Based Learning (Introduction). Retrieved October 16, 2014, from http://bobbyshaddoxtl.weebly.com/introduction.html. 
Silva, E., \& White, T. (2013). Pathways to Improvement Using Psychological Strategies to Help College Students Master Developmental Health. Palo Alto, CA: Carnegie Foundation for the Advancement of Teaching. Retrieved July 3, 2018, from http://www.achievingthedream.org/sites/default/files/resources/ PathwaysToImprovement_0.pdf.

Sitra Foundation. (2015, April 1). Towards a Sustainable Well-Being Society: From Principles to Applications (Sitra Working Paper).

Sizer, T. (2008). On Schools of Education. UnBoxed, (2).

Smith, F. (1998). The Book of Learning and Forgetting. New York: Teachers College Press.

Soep, E. (2008). Learning as Production, Critique as Assessment. UnBoxed, (2). Retrieved July 5, 2018, from http://gse.hightechhigh.org/unboxed/issue2/ learning_as_production/.

Soep, E., \& Chavez, V. (2005). Youth Radio and the Pedagogy of Collegiality. The Harvard Educational Review, 75(4), 409-434.

Szulwalski, L. (2015). Planting the Seed: Creating a Culture of Environmental Stewardship. Retrieved July 3, 2016, from http://lszuwalski.wix.com/ sldp\#!mastersproject/cswb.

Vasquez, A. (2012). Community Service Learning in the Elementary Classroom. Available at http://www.amazon.com/Community-Service-LearningElementary-Classroom/dp/147765092X.

Wagner, T., \& Dintersmith, T. (2015). Most Likely to Succeed: Preparing Our Kids for the Innovation Era (2nd ed.). New York: Scribner.

Whitehead, A. (1929). The Aims of Education. New York: The Free Press.

Wolfe, D. (1992). Assessment as an Episode of Learning. Assessment Update, $4(1), 5-14$.

\section{Web Resources}

Collegial Coaching Hub: http://collegialcoaching.weebly.com/.

High Tech High Home Page: www.hightechhigh.org.

High Tech High Graduate School of Education: http://gse.hightechhigh.org/. School Reform Initiative: http://www.schoolreforminitiative.org/. YouthTruth: http://www.youthtruthsurvey.org/. 
Open Access This chapter is licensed under the terms of the Creative Commons Attribution 4.0 International License (http://creativecommons.org/licenses/ by $/ 4.0 /$ ), which permits use, sharing, adaptation, distribution and reproduction in any medium or format, as long as you give appropriate credit to the original author(s) and the source, provide a link to the Creative Commons license and indicate if changes were made.

The images or other third party material in this chapter are included in the chapter's Creative Commons license, unless indicated otherwise in a credit line to the material. If material is not included in the chapter's Creative Commons license and your intended use is not permitted by statutory regulation or exceeds the permitted use, you will need to obtain permission directly from the copyright holder.

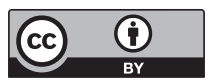

